\title{
Enfermedades relacionadas con los edificios
}

\section{Building related ilness}

\section{J. Boldú, I. Pascal}

\section{RESUMEN}

Tras los cambios realizados en los últimos años en los edificios modernos como sistemas de ventilación forzada, ordenadores, etc., se han descrito una serie de enfermedades relacionadas con ello. El presente trabajo se centra en el síndrome del edificio enfermo, que constituye un grupo de síntomas que lo padecen habitualmente trabajadores de un mismo edificio "enfermo" y relacionado con su ambiente interior, ya que comienza la clínica a las horas de entrar en el edificio y mejora a los minutos de alejarse de dicho ambiente. El origen probablemente sea multifactorial causado por contaminantes volátiles del aire interior del edificio, sistema de ventilación, factores relacionados con la organización del trabajo e incluso dependientes de huésped. Dado que no existe una única causa se enumeran los factores de riesgo para desarrollar dicho síndrome así como los pasos para llegar a su diagnóstico y medidas útiles para evitarlo.

Palabras clave. Edificio enfermo.

\begin{abstract}
Following the changes carried out in recent years in buildings, such as ventilation systems, computers, etc., a series of diseases, that are related to this, have been described. This paper concentrates on the syndrome of the sick building, which is formed by a group of symptoms normally suffered by workers in the same "sick" building. This syndrome is related to its interior ambience, since the clinical manifestations appear some hours after entering the building and improves a few minutes after leaving this ambience. The origin is probably multifactorial: volatile airborne pollutants, the ventilation system, factors related to work organisation, or even dependent on the host. Since there is no single cause, we enumerate the risk factors in developing this syndrome as well as the steps for reaching a diagnosis and useful measures for preventing the sick building.
\end{abstract}

Key words. Sick building.

An. Sist. Sanit. Navar. 2005; 28 (Supl. 1): 117-121.

Sección de Neumología. Hospital Virgen del Camino. Pamplona.

\author{
Correspondencia: \\ Joan Boldú Mitjans \\ Sección de Neumología \\ Hospital Virgen del Camino \\ Irunlarrea, 4 \\ 31008 Pamplona \\ Tfno. 848429660 \\ e-mail: jboldumi@cfnavarra.es
}




\section{INTRODUCCIÓN}

En las últimas décadas se han producido cambios sustanciales en los edificios modernos, principalmente en los destinados a albergar oficinas donde trabaja gran número de personas. Como consecuencia de factores diversos socioeconómicos, dichos edificios han sufrido importantes cambios tanto en su diseño, como en la generación de entornos de trabajo con una serie de características específicas, como son los sistemas de ventilación artificial, la proliferación de aparataje de oficina en forma de ordenadores, fotocopiadoras, impresoras etc., uso extensivo de materiales sintéticos, sistemas de iluminación fluorescente generales, presencia de contaminantes directos como el humo del tabaco, etc., que generan unos efectos para la salud que cada vez van siendo mejor conocidos.

Dichos entornos de trabajo se han relacionado con la presentación de una serie de patologías que se pueden clasificar de tres formas:

1. Pacientes con enfermedades ya conocidas que sufren empeoramiento clínico al permanecer en el edificio en el cual trabajan.

2. Enfermedades específicas producidas por causas identificables presentes en este medio.

3. "Síndrome del edificio enfermo".

Dentro del primer grupo se encuentran pacientes diagnosticados de asma bronquial, rinitis alérgica o dermatitis atópica, cuyos síntomas empeoran al permanecer en el interior de determinados edificios, bien en relación a la exposición a distintos alergenos presentes en dicho medio o a las condiciones microambientales del interior del edificio, sea en forma de irritantes volátiles, condiciones adversas de humedad, temperatura, etc. Para su diagnóstico e identificación se siguen las pautas establecidas en el estudio de la patología respiratoria ocupacional.

En el segundo grupo de enfermedades, su etiología está localizada en el propio edificio pudiendo ser de diversos tipos:

- Infecciosa: por transmisión de agentes infecciosos sea a través de los sistemas de acondicionamiento de aire como en la enfermedad de los legionarios; de persona a persona como la tuberculosis o las infecciones virales.

- Dispersión de antígenos del propio edificio como en las neumonitis por hipersensibilidad, fiebre de los humidificadores, etc.

- Tóxicas: por difusión de irritantes o tóxicos volátiles presentes en el ambiente como CO, formaldehído, órgano fosforados, etc.

En todas estas patologías existe una causa identificable por medios diagnósticos, debiéndose seguir las pautas metodológicas apropiadas para cada caso.

El "síndrome del edificio enfermo" se define como la situación en la que en un edificio determinado, más personas de lo normal manifiestan tener un conjunto de síntomas inespecíficos pero bien definidos, que desaparecen al abandonar el edificio. Incluye un grupo de síntomas de vías respiratorias altas y bajas, dermatológicos, oculares y sistémicos, que aparecen a las horas de permanecer en el interior de un edificio y mejoran tras alejarse de dicho ambiente. Deben de afectar a varios de los individuos que conviven en un determinado lugar. Se han desarrollado cuestionarios específicos para detectar síntomas entre los trabajadores de un edificio determinado, cuantificándolo numéricamente en forma del llamado "índice de síntomas del edificio", habiéndose detectado diferencias entre edificios "buenos" y "malos" de hasta 4 veces. Desde 1970 se han descrito casos de trabajadores en un mismo edificio, escuelas, hospitales e incluso domicilios.

\section{FACTORES ETIOLÓGICOS DEL SÍNDROME DEL EDIFICIO ENFERMO}

No se ha descrito una única causa responsable de su aparición por lo que se considera un problema de origen multifactorial incluyendo los siguientes factores: contaminantes volátiles del aire interior del edificio, sistema de ventilación del edificio, factores relacionados con la organi- 
zación del trabajo y factores dependientes del huésped.

\section{Contaminantes del aire interior del edificio}

Se trata de contaminantes volátiles procedentes de materiales aislantes, mobiliario, complementos de oficina, productos de limpieza, maquinaria etc. Los más habituales son:

- Componentes orgánicos volátiles: formaldehído, disolventes, compuestos desprendidos de impresoras $\mathrm{y}$ fotocopiadoras, pinturas $\mathrm{y}$ barnices.

- Polvo y fibras del ambiente interior: asbesto, fibra de vidrio, polvo de papel, papel autocalcable, descomposición de materiales de construcción, suciedad.

- Bioaerosoles: bacterias, hongos, virus, ácaros, excrementos y pelos de animales.

- Vapores de escape de vehículos y de la industria.

- Contaminantes generados por la actividad humana: dióxido de carbono, perfume.

- Humo del tabaco: en estudios donde se ha analizado, se ha demostrado el hecho de que los no fumadores que trabajan con fumadores presentan más síntomas que aquellos que se encuentran en un ambiente sin humo. Si se elimina el humo de tabaco disminuyen los síntomas.

- Otros: presencia de deterioro por humedades, pesticidas, radón, materiales del edificio, productos de la combustión del carburante etc.

\section{Ventilación y factores del propio edificio}

Se precisa una buena ventilación para disminuir la concentración de contaminantes ambientales que potencialmente puedan producir síntomas. En algunos estudios se ha relacionado el grado y tipo de ventilación con los síntomas; a menos ventilación mayor afectación clínica. Una proporción de ventilación mayor de 10 l/seg/persona parece disminuir la prevalencia de síndrome del edificio enfermo. Sin embargo, en otros, la relación obtenida ha sido inversa, atribuyéndolo a un inadecuado sistema de aire acondicionado (Ej. polucionantes y microorganismos generados en el sistema de conducción o contaminantes transportados a distintas zonas del edificio siguiendo los gradientes de presión de las distintas áreas de trabajo). En cuanto a los tipos de ventilación, la natural disminuye mucho la probabilidad de que se presenten síntomas, a pesar de que los rangos de humedad y temperatura no se encuentren entre los límites aconsejados. Cuanto más hermético es el edificio, más posibilidades de que se genere patología. Los factores físicos son importantes: temperatura mayor de $23^{\circ} \mathrm{C}$, humedad inferior al $40 \%$ o superior al $60 \%$, ruido, iluminación inadecuada, controles ambientales y de iluminación no ajustables por el usuario, aumentan la prevalecia de los síntomas. Techos bajos inferiores a 2,4 metros, amplias áreas de archivo de documentación en papel y servicios de mantenimiento del edificio ineficaz y con mala comunicación con los usuarios se han relacionado también con mayor prevalencia de síntomas.

\section{Factores relacionados con la organización del trabajo}

Un estatus bajo a nivel laboral, aumento del estrés y escasa satisfacción laboral, favorecen la aparición del síndrome del edificio enfermo. El espacio disponible por el trabajador y la concentración de máquinas de oficina en áreas determinadas favorecen también la aparición de síntomas. El número de horas pasadas delante de los monitores de ordenador también se ha relacionado con aumento en los síntomas.

\section{Factores dependientes del huésped}

Los síntomas predominan en el sexo femenino, con historia previa de atopia, hiperreactividad bronquial, asma o enfermedades de la piel.

Existe un determinado tipo de personalidad que favorece la aparición del síndro- 
me del edificio enfermo; son personas con un mayor grado de ansiedad, suspicacia y agresión.

\section{SINTOMATOLOGÍA ASOCIADA AL SÍNDROME DEL EDIFICIO ENFERMO}

Los síntomas más comunes son:

- Oculares: irritación, sequedad, picor.

- Nasales y faríngeos: obstrucción nasal es el más frecuente; posteriormente sequedad en la garganta, irritación y prurito. Rinitis con estornudos y rinorrea es menos frecuente.

- Respiratorios: tos, opresión torácica, disnea.

- Neuropsicológicos: el más prevalente es la astenia que de forma característica aparece a las horas de permanecer en un edificio (habitualmente en el trabajo), y mejora a los minutos de abandonarlo; otros menos frecuentes: cefalea, no migrañosa ni pulsátil, con sensación de presión en la cabeza; letargia, irritabilidad, dificultad de concentración, bajo rendimiento intelectual.

- Cutáneos: sequedad, picores, rash.

Estos síntomas los relaciona el paciente con un edificio determinado, habitualmente del medio laboral sobre todo oficinas, ya que es en este ambiente donde más se ha descrito este síndrome, aunque también se han dado casos en hospitales, colegios y domicilios. Lo característico es el inicio de los síntomas a las pocas horas de entrar en el edificio, y la mejoría de todos los síntomas excepto los cutáneos, a las horas de abandonarlo. Las alteraciones dermatológicas pueden tardar días en desaparecer. Estos síntomas no amenazan la vida del paciente pero conllevan bajas laborales y descenso de la productividad. Afectan con distinta intensidad a los distintos trabajadores, dependiendo de los microambientes donde estén ubicados y de la susceptibilidad individual.

\section{FACTORES DE RIESGO PARA DESARROLLAR SÍNDROME DEL EDIFICIO ENFERMO}

Dado que no existe una única causa capaz de desencadenarlo se han sugerido distintos factores relacionados tanto con el edificio y su ambiente interior, como con el individuo que facilitan su desarrollo.

Relacionados con el edificio:

- Problemas de mantenimiento y limpieza.

- Equipos de oficina modernos: ordenadores.

- Grandes áreas de archivos (papel) próximas al personal.

- Ventilación artificial.

- Edificios grandes.

- Controles ambientales centralizados, no locales.

- Edificios viejos o recientemente remodelados.

- Amplias zonas de moquetas, revestimientos.

Relacionados con el ambiente interior:

- Humedad ambiental baja ( menor de $40^{\circ}$ ) o excesiva (mayor de $60^{\circ}$ ).

- Poca renovación del aire con aporte exterior (menos de 10 l/seg/persona).

- Humo de tabaco en el ambiente interior.

- Zonas de humedad visible.

- Liberación de contaminantes: polvo, disolventes, emisión de fotocopiadoras e impresoras.

- Iluminación fluorescente en mal estado.

- Temperatura excesiva (más de $23^{\circ} \mathrm{C}$ en edificios con aire acondicionado).

- Ruidos ambientales.

Relacionados con el individuo:

- Sexo femenino y joven.

- Enfermedades previas: atopia, asma.

- Problemas psicosociales. 
- Menor jerarquía en el puesto laboral.

- Estrés y desencanto laboral.

\section{APROXIMACIÓN AL PROBLEMA}

Ante la sospecha clínica de un paciente con "síndrome del edificio enfermo", el clínico deberá realizar una historia minuciosa detallando las actividades laborales y su ambiente. Se deberá interrogar sobre exposiciones, temperatura, humedad, iluminación, ventilación, así como cambios realizados en el edificio. Incluirá datos sobre satisfacción en el trabajo, estrés y relaciones entre compañeros y sus superiores. Se intentará relacionar temporalmente los síntomas con la estancia dentro del edificio y su mejoría tras abandonarlo. Se excluirán patologías previas del paciente que se agraven en dicho ambiente.

El diagnóstico del síndrome del edificio enfermo se realizará si tras el interrogatorio previo, el paciente y otras personas relacionadas con el mismo edificio presentan síntomas compatibles con esta patología.

Posteriormente se pondrá en conocimiento de la persona encargada del mantenimiento (ingeniero experto en sistemas de ventilación, arquitecto, higienista...), para evaluación de la calidad del aire del edificio, medición de contaminantes, evaluación del sistema de ventilación, etc. y actuar en su mejora.

Si los síntomas persisten al separar al paciente del "edificio enfermo" se remitirá para estudio al especialista correspondiente.

\section{MEDIDAS ÚTILES PARA EVITAR EL "EDIFICIO ENFERMO"}

- Mejorar los sistemas de ventilación de los edificios y su mantenimiento (tasa de renovación del aire mayor de $10 \mathrm{l} / \mathrm{seg} /$ persona).

- Ventilación natural.

- Evitar problemas de humedades.

- Evitar materiales con componentes volátiles.

- Buena limpieza de los edificios.

- Espacio suficiente para los trabajadores.

- Equipos de oficina en áreas con adecuada ventilación.

- Regulación local de temperatura, humedad, ruido e iluminación.

- Crear buen ambiente laboral en los trabajadores y sus superiores.

- Evitar situaciones de estrés laboral.

- Ambiente interno del edificio libre de humo.

\section{BIBLIOGRAFÍA}

1. BuRGE PS. Sick building syndrome. Occup Environ Med 2004; 61: 185-190.

2. Hodgson M. Indor environmental exposures and symptoms. Environmental Health Perspectives 2002; 110; 663-667.

3. Redlich CA, Sparer J, Cullen MR. Sick building syndrome. Lancet 1997; 349: 1013-1016.

4. Menzies D, Bourbeau J. Building-related illnesses. N Engl J Med 1997; 337: 1524-1531.

5. $\mathrm{ABC}$ of work related disorders. Building related illnesses. Br Med J 1996; 313: 674-677.

6. Gold DR. Indoor air pollution. Clin Chest Med 1992; 13: 215-229. 